\title{
Design of Coal mine Multi-joint Snake-like Rescue Robot Based on ARM
}

\author{
Hongyan $\mathrm{Li}^{1, \mathrm{a},{ }^{\star},}$, Yuanbin $\mathrm{Hou}^{2, \mathrm{~b}}$ \\ ${ }^{1}$ College of Electrical and Control Engineering, Xi' an University of Science and Technology, Xi'an \\ Shan'xi 710054,China \\ ${ }^{2}$ College of Electrical and Control Engineering, Xi' an University of Science and Technology, Xi'an \\ Shan'xi 710054,China \\ a lihongyan@xust.edu.cn, b houyb@xust.edu.cn, \\ *Corresponding author
}

Keywords: Snake robot, Actuator, Servo, ARM, Wireless.

\begin{abstract}
In order to make the coal mine snake-like robot can better perform search and rescue missions in different terrain environment, according to the characteristics of the snake like robot, a new front end actuator was designed. According to the faults of traditional snake like robot head only has sensor without actuator, The method of 4 degree of freedom is proposed as the front end effector, the hardware platform is built with ARM7-LPC2132 as the controller, L298N as the motor driving module and LCD screen 12864 as the man-machine interface. Through a wireless router WR703n Mortimer S608 camera data can be transferred to the host machine, By the wireless data transmission module the host machine can real-time control the lower machine, temperature measurement, smoke alarm, mechanical arm in addition to the barrier, which can complex terrain and a device field detection. The program is written with $\mathrm{C}$ and $\mathrm{C \#}$ language. After debugging, the function of the clamping and handling of the obstacle etc. can be achieved. The wireless remote control distance can reach 100 meters, and the communication effect is stable and reliable.
\end{abstract}

\section{Introduction}

In recent years, coal mine disasters around the world, it is often accompanied by vigorous shaking of the ground and cracks in the ground. Make various types of buildings to collapse and damaging, making communication system disruption ${ }^{[1]}$. Toxic and hazardous gas leaks, fires, plague, and leaks of radioactive material secondary disasters have caused the disaster, and all kinds of terrain. In the history of mankind, each disaster has brought us great damage, disaster relief work is particularly important, small and secondary disasters occurred in search-and-rescue stations, you need a flexible search and rescue equipment, to collect field data, so that we know the scene. Snake-like robot flexibility, you can work in narrow terrain such as collapsed buildings. Will make the next aid more targeted $^{[2]}$. With the rapid development of science and technology, leap in technology led to the development of intelligent, snake-like robot technology has attracted more and more attention, study of snake-like robot system has become the science of a dynamic, challenging front direction.

The snake-like rescue robot using the snake's movement, can adapt to a variety of complex terrain, especially after the earthquake, a mining disaster environment, they have many obstacles, terrain narrow, space environment hazards, risk factors such as easy to produce flammable gas, snake-like rescue robot can flexibly respond to these environments, complete the search and rescue mission, for search and rescue work to save valuable time.

\section{Mechanical Structure Design of Multi-joint of the Snake-like Robot}

In nature, snakes are vertebrates, its cones about 200-400 of Ridge spine, spine formation snake ball sleeve joint, and with projections, it prevents the body twist, and protect the notochord. The snake 
body musculoskeletal mechanics movement is very complex. In order to simplify the process, reduce costs, here the model of snake robot design consists of 9 modules, 8 joints, the simplified model is schematically shown in figure 1 . And with the servos as the joints connecting piece, make its have XY plane winding motion and linear motion ${ }^{[3]}$.

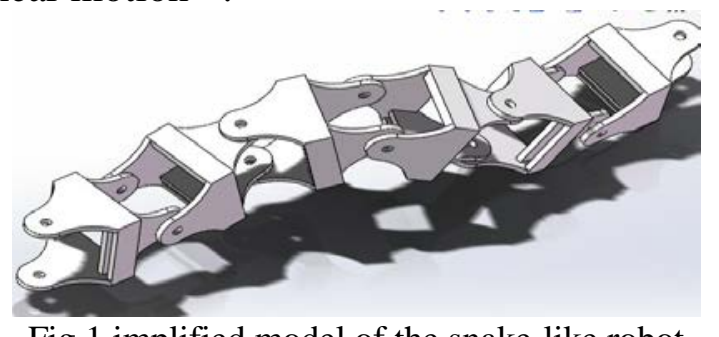

Fig.1 implified model of the snake-like robot

The 8 joint of the snake-like robot angle in accordance with sinusoidal approximation of change ${ }^{[1]-}$ ${ }^{[3]}$,of which 4 joint can form an approximate sinusoidal waveform, 2 joint angle adjacent differs by 1/4 cycles. Each joint is sequentially contact and the ground, so that the snake like robot wavy forward. The movement form as shown in figure 2.

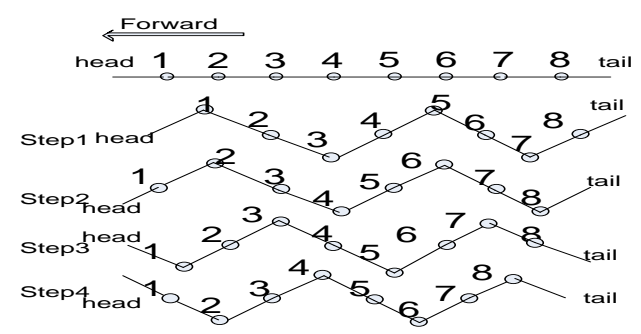

Fig.2 rajectory of the snake-like robot

Considering the experimental stage of the snake like robot strength and stability, the snake's body is connected together with elliptic acrylic sheet glass, joint driven by the Fraser MG995 type copper metal gear servo actuator.

\section{Design of the whole System}

RF wireless remote control system of multi joint of the snake like robot is divided into three functional parts: PC, handheld remote controller (wireless communication transmission device), hypogynous machine (multi joint snake robot). Through the RS232 serial communication between host computer and the remote controller. Front end body of the snake-like search-and-rescue robots use WR703n and LPC2132 As the core. Using 12864 LCD screen with Chinese font to achieve human-computer interaction. Wireless remote control block diagram of the overall system as figure 3 shows.

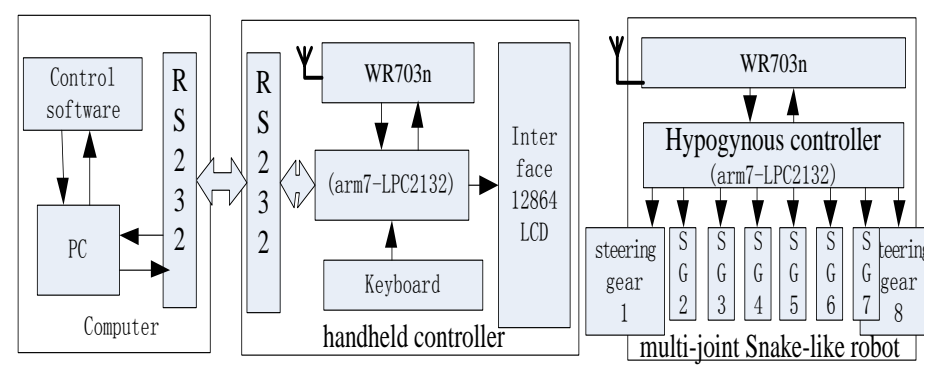

Fig.3 system diagram of multi joint robot wireless remote control

\section{Hardware Design of System}

The Core Controller and Power Supply System. The controller uses the LPC2132 development board.LPC2132 is based on a real-time simulation and embedded track ARM7 TDMI-STM CPU 32-bit microcontroller and embedded with $64 \mathrm{kB}$ high-speed Flash memory. 128-bit wide memory 
interface and the unique accelerator structure enable 32-bit code to run at maximum clock rate. Multiple 32 bit timer, and one 10 bit 8 roads ADC, and PWM channel and 47 a GPIO and up to 9 an edge or level triggered of external interrupted makes they special applies $\mathrm{Yu}$ industrial control and medical system $^{[4]}$. to guarantee range capacity, System powered part used ACE 30C 3500mAh 7.4V lithium RC airplane battery, use a regulated power supply module 7805 and 1117 respectively provides power to the servo and the main control chip. Robotic arm on the 4-way servo, due to its driving voltage needed to reach $7.4 \mathrm{~V}$, use LM7808 as the regulator power supply. A route module WR703n, in order to prevent external interference on the module, safeguard the stability of their work, and applies the $5 \mathrm{~V}$ power for its electricity supply, which ensures the stable operation of the system as a whole.

Actuator Selection and Control Methods. Taking joint link element actuator design of snake like robot, actuator is integrated the DC motor, motor controller and the speed reducer, and is packaged in a convenient installation of the shell of the servo unit[5]. Through the use of simple input signal, the motor system can be given the exact rotation angle. This paper adopts the Fraser brand MG995 type copper metal gear servo actuator, the following parameters of the servo actuator, the servo parameters are as follows ${ }^{[6]}$ :

Working voltage: $3.0 \mathrm{~V}-7.2 \mathrm{~V}$

Static current: less than $3 \mathrm{~mA}$ ( $4.8 \mathrm{v}$ power supply)

Speed: $0.17 \mathrm{sec} / 60$ degrees no load speed (4.8V) and $0.13 \mathrm{sec} / 60$ degrees (6.0V)

Torque: $13 \mathrm{KG} / \mathrm{cm}$

Working dead zone: 4 micro seconds ${ }^{[7]}$

Dimensions: $40.7 * 19.7 * 42.9 \mathrm{~mm}$

Weight: $0.055 \mathrm{~kg}$

The control circuit of the servo uses integrated circuit CN9068 as the core, with very few external components ${ }^{[8]}$. Servo wide range signal to $1.0 \mathrm{MS} \sim 2.0 \mathrm{MS}$, the corresponding angle is -90 degrees $\sim+90$ degrees.

MG995 servos control diagram is shown in Figure 4.

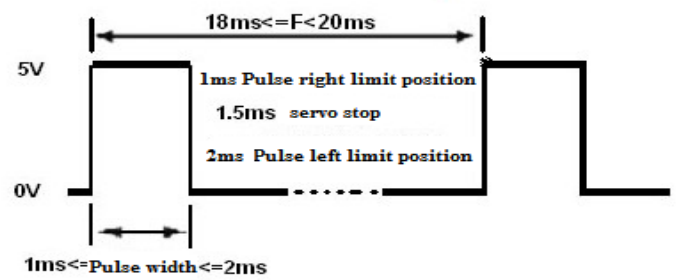

Fig.4 MG995 servo signal control chart

4-DOF manipulator module physical is shown in Figure5.

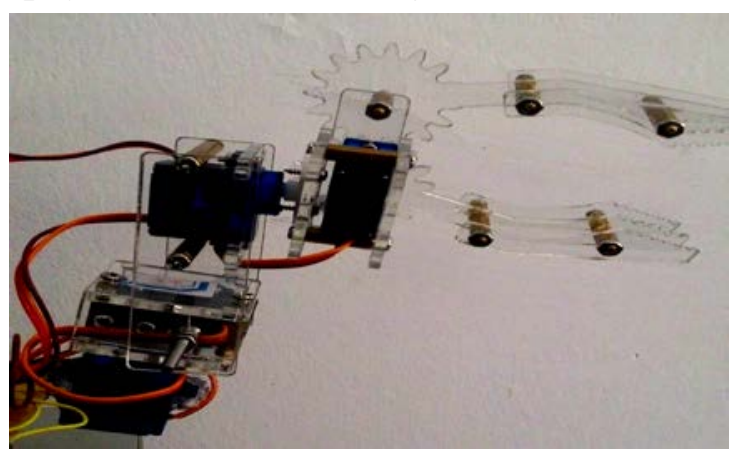

Fig.5 4DOF manipulator module

Motor driver circuit. Provide power to the front end of the snake rescue robot is DC motor, here the use of L298N on the drive. Chip L298N drive voltage of 5 volts to 35 volts, logic voltage 5 V DC, the working current of the logic for $0 \mathrm{Ma}$ to $36 \mathrm{Ma}$, drive current, the largest single bridge for 2 AMPERES, the storage temperature of - 20 DEG C to +135 DEG C, the maximum power is 25W[9]. 
The driving circuit of the design is shown in Figure 5, in which the diode is a continuous current diode and the capacitor is a filter capacitor. When the L298N enable end is low, the running state is stopped. Under any of the following circumstances when the terminal is high normal: input 1 is a high level, input 2 for low level, the running state of the motor is transferred; input 1 for low level, input of 2 for the high level, the motor running state inversion; input 1 is a high level, input of 2 for high level; the motor running state brake stop. The input terminal 1 is low, the input terminal 2 is low, and the motor running state is stopped. The schematic diagram of the L298N drive circuit is shown in figure 6.

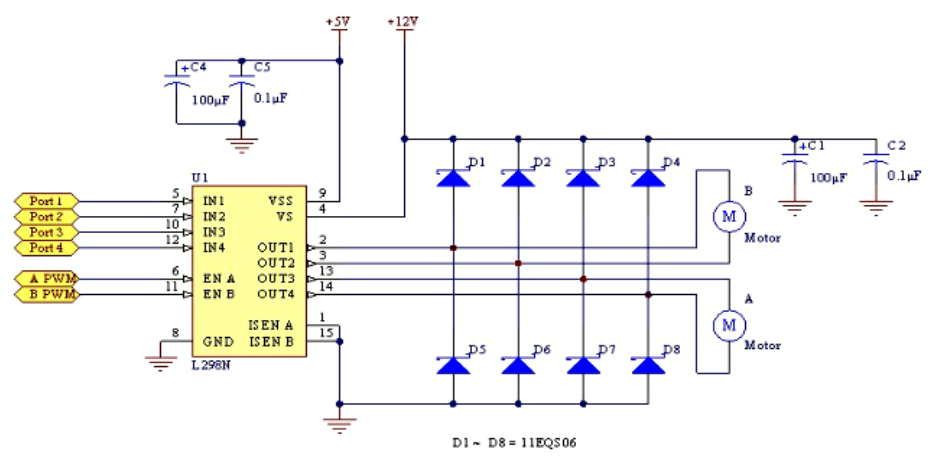

Fig.6 298N Drive circuit diagram

Wireless circuit. Steering remote control using the wireless module wireless module NRF24L01 Wireless module wireless module in the open fields measured control distance $100 \mathrm{M}$ 。 Working voltage is 1.9 volts to 3.6 volts between the speeds of $54 \mathrm{Mbps}$, because air transmission rate is very short, so avoid collisions in the wireless transmission, support for multiple frequency work, a total of 125 A frequency, able to meet the needs of multipoint communication and frequency-hopping communication needs. Built-in module small $2.4 \mathrm{GHz}$ antennas. In order to reduce current consumption when working in answer mode when, start up time reduced speed in space, thus reducing the consumption of electricity. NRF24L01 integrates all RF high-speed signals processing part of the Protocol-related part. NRF24L01 wireless module circuit diagram as Figure 7 shows.

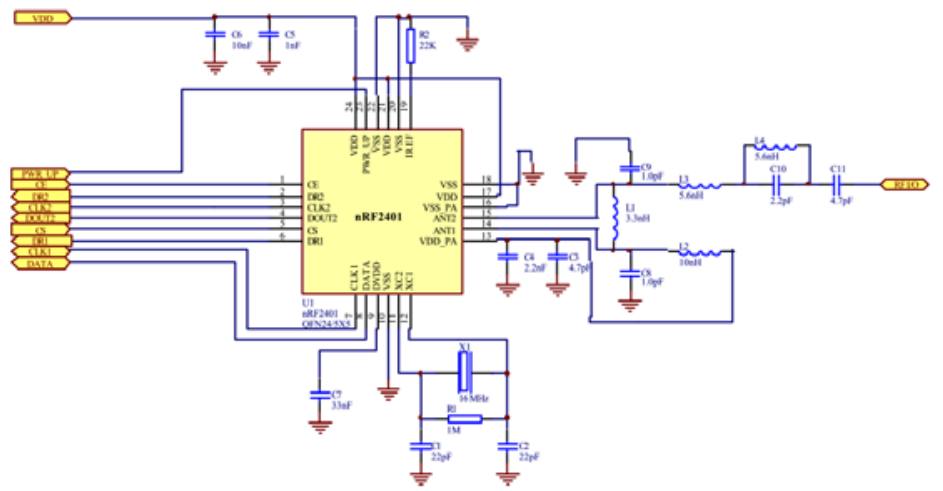

Fig.7 NRF24L01 module schematic diagram

In addition, also designed to detect combustible gases and smoke MQ2 Sensor modules, and can detect temperature ds18b20 Digital temperature sensor circuit.

\section{Software Design of System}

System main program is written by using of $\mathrm{C}$ language, each function module of the program are composed by the main program and some subroutine, the main program includes GPIO port defined initialization and NRF905 configuration program. System program mainly includes wireless communication subroutine, sine wave motion of snake like robot control subroutine and the algorithm subprogram. A Periodic Pulse Width Setting of MG995 Servo is shown in table 1. 
Table1 A Periodic Pulse Width Setting of MG995 Servo

\begin{tabular}{llccr}
\hline Order & Step1 & \multicolumn{1}{c}{ Step 2 } & Step 3 & \multicolumn{1}{c}{ Step 4 } \\
\hline $1-5$ & $-90^{\circ}(0.5 \mathrm{~ms})$ & $0^{\circ}(1.5 \mathrm{~ms})$ & $90^{\circ}(2.5 \mathrm{~ms})$ & $0^{\circ}(1.5 \mathrm{~ms})$ \\
$2-6$ & $0^{\circ}(1.5 \mathrm{~ms})$ & $-90^{\circ}(0.5 \mathrm{~ms})$ & $0^{\circ}(1.5 \mathrm{~ms})$ & $90^{\circ}(2.5 \mathrm{~ms})$ \\
$3-7$ & $90^{\circ}(2.5 \mathrm{~ms})$ & $0^{\circ}(1.5 \mathrm{~ms})$ & $-90^{\circ}(0.5 \mathrm{~ms})$ & $0^{\circ}(1.5 \mathrm{~ms})$ \\
$4-8$ & $0^{\circ}(1.5 \mathrm{~ms})$ & $90^{\circ}(2.5 \mathrm{~ms})$ & $0^{\circ}(1.5 \mathrm{~ms})$ & $90^{\circ}(0.5 \mathrm{~ms})$ \\
\hline
\end{tabular}

Snake-like robot motion is driven by 8 servo of 8 joints, 8 servo actuators can be composed of two cycles of a sine wave ${ }^{[1-3]}$, so the snake like robot moving process is essentially sinusoidal forward transfer. And as you can see from Figure 2, 4 servo actuator composed of a sine wave cycle, so in advance of the snake like robot process, No. 1 and No. 5 joint is always synchronized, similarly, 2 and 6, 3 and 7, 4 and 8 joint were also is always synchronized, and the differential phase between 1/4 cycle No.1 and No.2 joint, joint between each other, adjacent joint are also a difference of 1/4 cycles. So control subroutine is compiled in the locomotion of the snake robot, servo pulse width data compiled a periodic motion as a table as shown in Table 1, and then in accordance with the change of the pulse width to form the timing of each joint of the steering gear, through the look-up table method is simple and efficient, can achieve sinusoidal whole movement of the robot body. Snake like robot wireless remote controller main program flow shown in figure8.

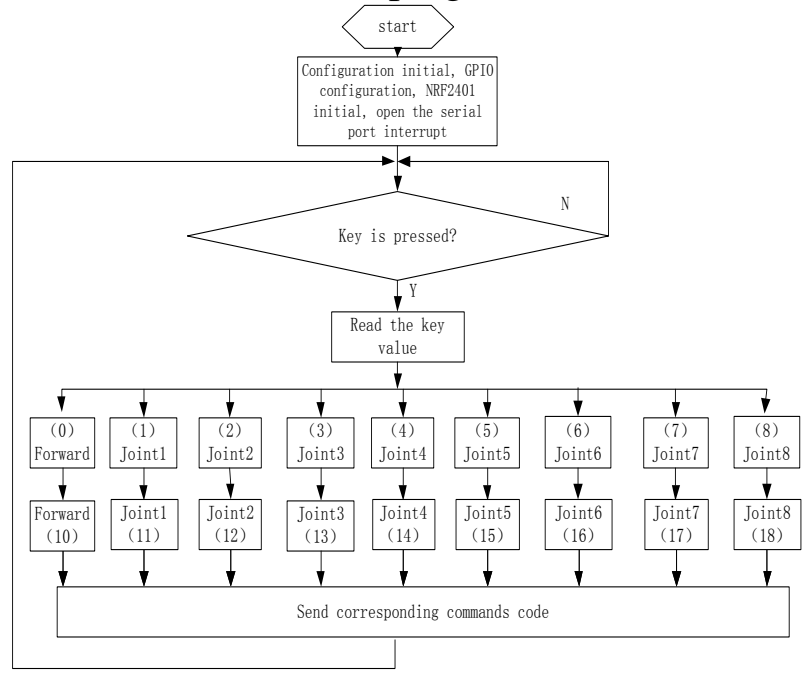

(a) the main program flow chart of remote control

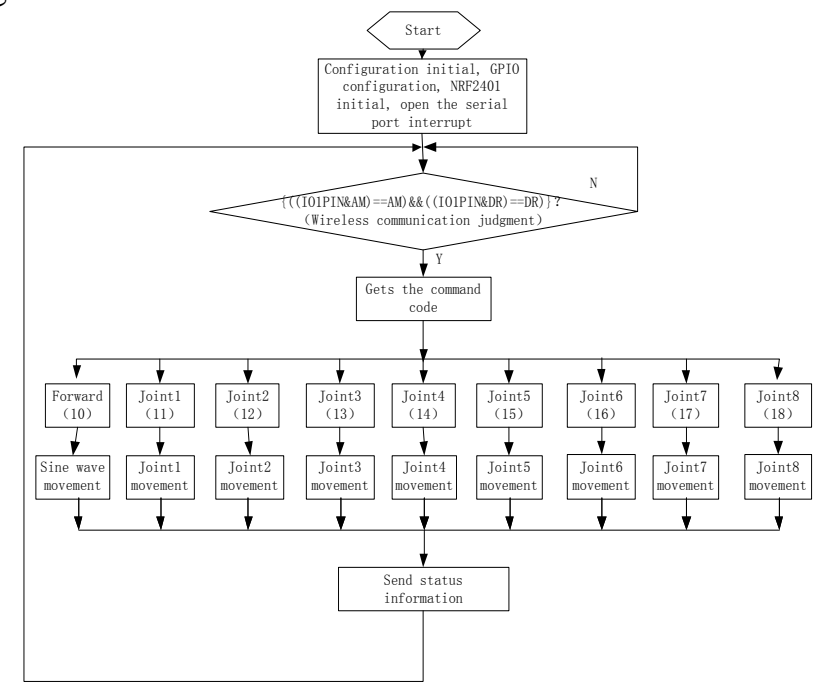

(b) 8 joint snake-like robot main program flow chart Fig.8 Flow diagram of system program

\section{PC interface}

PC interface written using VC6.0, through the serial port to realize the wireless control of the snake like robot, the operation interface as shown in figure 9.

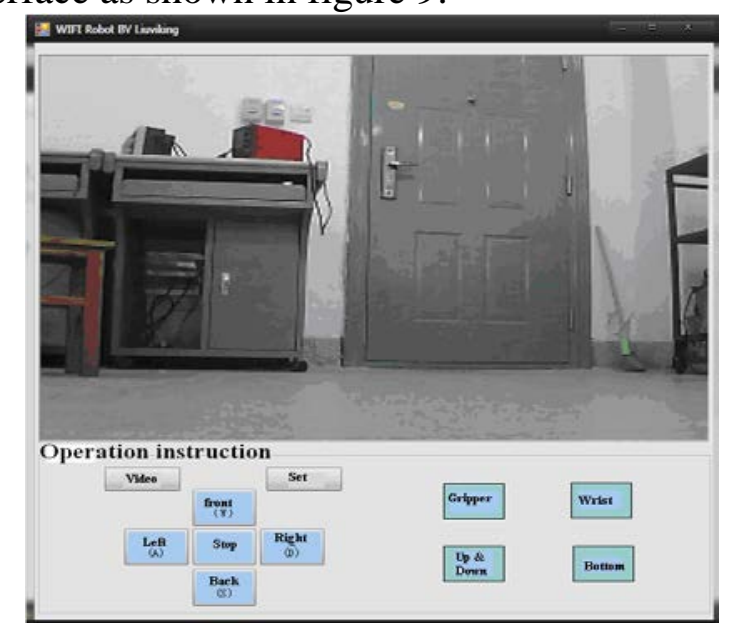

Fig.9 Interface of PC control program 


\section{Summary}

This paper mainly completed the design and manufacture of the 8 joint of snake like robot body and the wireless remote control system. The system hardware mainly completed the design, production design of snake like robot shape gear driven module, power supply module, wireless communication module. The software of the system to realize the function of the system as the goal, uses the modular structure design. This system has realized the expected function, can be well simulated snake winding and linear motion, and capable of wireless control of the snake like robot is performed by the host computer, the software part of the system is designed to realize the function of the system. The system realizes the function of the expected plan, can achieve a good monitoring of the surrounding environment, to grab and clean the obstacles, the wireless control distance can reach 100 meters, and stable and reliable. The snake robot motion control algorithm is simple, low cost, simple and convenient steering gear speed regulation, stable operation; follow the good performance, stable operation of snake like robot, the program is universal.

\section{Acknowledgement}

This work was supported in part by the Foundation of Youth Cultivation Fund Project of Xi'an University of Science And Technology-- Research on Key Technologies of multi joint snake like robot. China (No.2013103).

\section{References}

[1] He Haidong, Wang Guangrong, Cao Zhikui. three of eight joint lever movement simulation of snake-like robot . upload technology, 2004 (12): 31-34

[2] Zhu Sheng collar, Guo Xuhong, Rui Yannian. a new kind of snake-like robot motion planning research. Mechanical design and research, 2004, 20 (5): 23-25.

[3] Zhang Jiafan, Yang Canjun, Chen Ying, etc. worming robot research and development. Journal of mechanical engineering, 2005, 41 (5): 205-209..

[4] The week renders meritorious service, Susan. Easy ARM7-LPC213X/214X. Beijing: Beijing University of Aeronautics and Astronautics press, 2005.6 P45-78.

[5] Masashi S, Masakazu F, Tetsuya I. Serpentine locomotion with robotic snakes. IEEE Control Systems Magazine, 2002, 22(1):64-81.

[6] Hirose S,Moil M.Biologiclaly inspired snake-like robots. Proceedings of the IEEE International Conference on Robotics and Biomimetics. Shenyang, China, 2004.1-7.

[7] Xu Yu, Han,Li ping. AVR Design of servo controller. Industrial control computer, 2004, 17(11):38-39, 42.

[8] Wang Yanget al. The snake-like robot control system design and implementation. Robot, 2003, 25(6): 491- 494.

[9] Ye Chong, Kong Fanrang, Shu Genrong. snake-like robot based on AVR servo control, mechanical and electronic, and 2009.12:68-70. 